\title{
Medicinal Plant Research: 1953-1987
}

Varro E. Tyler ${ }^{1}$

Received: October 2, 1987

\begin{abstract}
Founding of the present Society for Medicinal Plant Research on April 8, 1953, took place amidst a number of significant events. The discovery of reserpine, tetracycline, and norethindrone, the beginning investigation od the cataranthus alkaloids, as well as the development of refined chromatographic procedures and radioactive tracer techniques for biosynthetic studies, all provided considerable impetus to the investigation of drug plants.

In the 35 years following, great progress has been made in physical analytical methods, but bioassay procedures are little improved. Appreciable advances have occured in the production of plant materials, particularly utilizing cell- and tissue-culture techniques. Fields that have attracted intensive study include alkaloid biosynthesis, psychotropic drugs, plant chemotaxonomy, antibiotics, catharanthus, rauwolfia, the chamomiles, ergot, milk thistle, and various herbal remedies. An overview of the research efforts in each of these areas is presented.

Although much of basic interest has been learned, practical results have been modest. The only new, commercially successful drugs of proven value that have been isolated from higher plants during the entire period are vinblastine and vincristine. Still, there is reason for optimism. Highly refined research methodologies and instrumentation are sure to yield favorable results eventually. The most productive period of medicinal plant research almost certainly lies in the future.
\end{abstract}

\section{Introduction $^{2}$}

The historical facts of scientific development and discovery in any field are not easy to assemble and are even more difficult to systematize. Scientists are too busy making history to bother to record it properly, so much of interest is lost. Many fields of endeavor, including plant drug research, are so broad that one gets the feeling of being an observer at a gigantic circus with multitudes of rings - not just the conventional three - featuring countless performers and performances on a nonstop basis. Probably the best that can be done in an attempt to present the events in a coherent fashion is to concentrate on a few of the truly significant acts, i.e., discoveries, and permit the interested reader to pursue elsewhere the details of any individual topic.

Even the main events may be controversial. All of us are captives of our own intellectual interests and experiences. If the ones I have selected do not agree with your own ideas, keep in mind that 35 years of diligent investigation conducted by numerous persons cannot be comprehensively reviewed in a few minutes. My choices reflect my own prejudices.

On April 8, 1953, when the Society for Medicinal Plant Research was founded under a slightly different name, many events of great importance were taking place in the field of natural drug products. In September of 1952 , Swiss scientists

\footnotetext{
${ }^{1}$ Hovde Hall, Purdue University, West Lafayette, Indiana 47907 , USA.

${ }^{2}$ Because of the comprehensive nature of this relatively short review, most references are to review articles or books providing summaries of the events discussed rather than to the original literature.
}

had published a paper identifying a new alkaloid, reserpine, as being responsible for much of the sedative and antihypertensive effects of Rauwolfia (1). The first gas-liquid chromatographic apparatus was developed that same year by English investigators (2). During 1953 itself, workers in Canada demonstrated that tyrosine was the metabolic precursor of hordenine (3). American groups that same year isolated tetracycline from a mixture of antibiotics produced by Streptomyces aureofaciens (4) and, as if that were not enough, characterized the norethindrone produced from yam diosgenin as the first oral contraceptive chemical (5). The very next year, 1954, another American carried out a nine-month's study of plants with interesting histories of use as folklore remedies and identified Catharanthus roseus as one of the more promising ones for future phytochemical and physiological investigation (6).

All of these events, relatively inconsequential in themselves, were the first steps in exceedingly important developments in the field of medicinal plant research. The discovery of reserpine, the first therapeutically useful tranquilizer of natural origin, led eventually to a revolution in the care and treatment of the mentally ill and of persons suffering from hypertension as well. Gas-liquid chromatography was one of a series of important developments in the field of instrumentation that greatly facilitated analysis of plant material. The work on hordenine foretold some two decades of intensive study on alkaloid biosynthesis using radioactively labeled precursors to trace the successive biochemical steps. Tetracycline and the birth control "pill" have probably been responsible for greater societal changes than all of the wars ever fought. If cancer is finally conquered, it will be due in large measure to the impetus provided by the work on catharanthus alkaloids.

\section{Analytical Methods}

Much of the progress achieved in medicinal plant research in the last 35 years has been due to the analytical instruments and methods developed and employed in that period. Paper chromatography was in its heyday in the early 1950's, but, in 1956, a startling development by Egon Stahl made available a technique that eventually replaced it (7). When Stahl published his paper on thin-layer chromatography (TLC) in Die Pharmazie, most readers probably assumed it was just another chromatographic gimmick. But his convenient spreader for plate preparation made TLC a truly useful method. By 19611962 , the first surveys of TLC methods and applications began to appear; the technique became widely used and remains of considerable importance to this day.

In 1967-1969, high-performance liquid chromatography (HPLC) caused renewed interest in, and increased application of, the earlier method of liquid chromatography (8). More recently, a number of innovative modifications of various types of 
chromatographic techniques have been developed and applied in attempts to achieve better separation of mixtures of plant products. These include droplet countercurrent chromatography, rotation locular countercurrent chromatography, vacuum liquid chromatography, high-performance thin-layer chromatography (HPTLC), overpressure layer chromatography (OPLC), and combination methods, such as OPLC/ HPTLC. How many, if any, of these "improved" techniques will become standard laboratory procedures remains to be determined.

In the 1960's, two spectral methods, nuclear magnetic resonance spectroscopy and mass spectrometry, began to be widely applied to plant analysis. Both types of instruments had been available for years, but advances in electronics and improved methodologies rendered them much more useful and certainly more available. The same may be said for X-ray crystallographic analysis as a method of structure determination.

Inevitably, methods combining spectral analysis with chromatographic techniques appeared, particularly in the form of mass spectrometry (MS) and gas chromatography (GC). Utilization of so-called $\mathrm{GC} / \mathrm{MS}$ allowed the direct identification of separated compounds. One of the most recent innovations has been the development of multiple stage or tandem mass spectrometry (MS/MS). This allows positive identification of nanogram quantities of constituents in tissue samples approximating $1 \mathrm{mg}$ without prior extraction or purification (9). The extreme sensitivity of this method and of radioimmunoassay procedures as well has proven extremely useful in the analysis of the contents of single cells selected for the purpose of progagating high-yielding strains of plant-cell cultures. Truly, analytical instrumentation and its application have made enormous strides in the last 35 years.

\section{Bioassay Procedures}

One of the continuing sources of frustration to the natural product chemist has been the difficulty in determining the general physiological activity of plant materials, whether in the form of crude fractions or as purified chemical entities. During most of the 35-year period under consideration, there has been no relatively simple, easily applicable technique available to investigators for this purpose, with the possible exception of methods for determination of antibiotic and anticancer activity. As a result, activity-directed screening of plants has been quite limited, and as much or even more effort has been expended on the isolation and identification of physiologically inert natural compounds as on their more significant active counterparts.

Perhaps the best available multipurpose technique has been the rat "Hippocratic" screen conceived in 1954 and developed into a standardized form by Malone and Robichaud in 1962. Details of an improved version were made available in $1976(10)$. The method basically involves the observation of a large number of parameters in rats for periods of time ranging from 5 minutes to as much as 7 days following administration of the test material. Although the method is capable of yielding much useful information, it does require a relatively skilled observer to record and evaluate the results.

In 1982, Meyer et al. reported considerable success with a simple bioassay utilizing brine shrimps (Artemia salina). After hatching in a brine solution, the shrimps are exposed to varying concentrations of the test material and an $\mathrm{LC}_{50}$ value in $\mu \mathrm{g} / \mathrm{ml}$ is calculated. It has been determined that the activities of a broad range of compounds are manifested as toxicity to the shrimp.
The method is rapid, reliable, inexpensive, and may be conveniently applied in-house by chemists, botanists, or others who lack the resources and the technical ability required to carry out standard bioassays. For just these reasons, it has been successfully applied by Trotter et al. to an investigation of Mexican folk remedies for potential pharmacological activity. McChesney and Adams have also used it to evaluate about 80 species of plants as potential sources of compounds with useful biological activities (9).

Another simple bioassay that is still in a rudimentary stage of development but which shows considerable promise for the future is the so-called potato-disc assay. This involves observation of the inhibition of crown-gall tumors induced on potato discs by Agrobacterium tumefaciens with various plant extracts or constituents being screened in a preliminary fashion for their anticancer potential. Results so far have been encouraging and have correlated well statistically with other much more elaborate and costly cell-culture procedures, at least for certain kinds of antitumor activity (9).

Even more simple and reliable bioassay procedures, perhaps involving the use of monoclonal antibodies, are certain to be developed and widely utilized in the future. They will provide a great stimulus to the study of medicinal plants and their active constituents.

\section{Production of Plant Material}

Because of the relatively minor economic importance of drug plants, little effort has been expended during the past 35 years on such classic agronomic research topics as plant breeding, the determination of optimal nutritional and environmental conditions, and innovative harvesting methods. Schieder (11) has noted that, genetically speaking, most cultivated medicinal plants are still "wild" types. Exceptions are Papaver somniferum, $P$. bracteatum, Cinchona spp., Digitalis lanata, Chamomilla recutita, and Mentha piperita. In terms of providing detailed information on drug plant cultivation, Heeger's 30year-old volume, Handbuch des Arznei- und Gewürzpflanzenbaues, remains the standard reference work (12).

That is not to say the field has been totally devoid of interesting developments. In the 1950 's, much attention was focused on the development of inoculating methods and machinery, harvesting techniques, and separation procedures required for the large-scale field cultivation of the ergot fungus (13). Although major developments have not taken place since 1960 , the procedure is still of considerable importance in some parts of the world, as witnessed by the 1985 publication titled Ergot Production in India (14).

Production of morphine from poppy straw, that is, from the dried capsule walls and stems of the plant instead of from the exuded latex, is a development primarily of the period being discussed. In 1951 , only $16 \%$ of the world's morphine production derived from poppy straw; by 1971 , the figure had reached $37 \%$ (15).

The discovery in 1963 by Neubauer and Mothes (16) of a new chemical strain of Papaver bracteatum, the alkaloid content of which was $98 \%$ thebaine, certainly offered great potential in the fight against drug abuse. The fact that thebaine could readily be converted into medicinally useful codeine offered a source of the latter without concomitant production of the more addicting morphine. Unfortunately, its potential has not yet been realized. Although agronomic research on the plant has continued (17), political and economic considerations primarily 
have prevented significant development of this useful discovery. $P$. bracteatum is not even mentioned as a useful drug plant in Ebert's recent volume on drug plant cultivation (18).

Some progress has been made in harvesting methods for drug plants. Since 1962, mechanical chamomile pickers have been employed in Germany, and they are continually being improved. Likewise, fruit capsules of the milk thistle, formerly cut off by hand at some risk to the harvester, are now combined (cut and threshed) by automatic machinery (18).

From the strictly scientific viewpoint, the real progress during recent years in the production of plant material has taken place not in field cultivation but in plant-tissue and, especially, plantcell culture. Just 30 years ago, the first alkaloid production in culture was reported (19). In 1980, Nickell (20) noted 54 different types of substances, ranging from alkaloids and antimicrobial agents to steroids and vitamins, as reportedly produced by plant-cell and plant-tissue cultures in vitro. Included were 82 different types of alkaloids, 7 benzoquinones, 39 enzymes, 18 plant acids, 32 pigments, and 41 steroids and saponins produced by hundreds of species of plant cultures.

Present limitations of such techniques include slow growth, expensive media, and the difficulty of recovering metabolites that are often stored in the cells rather than being excreted into the culture media where they could be more easily recovered. Therefore, production is economical only when the compounds produced are both costly and unique. Compounds which might presently approach commercial feasibility include diosgenin from Dioscorea deltoidea, serpentine from Catharanthus roseus, and ubiquinone-10 from Nicotiana tabacum (9).

Thirty years of intensive research have not yet developed cell and tissue culture of plants into methodologies appropriate for the large-scale production of drugs. Before that can take place, strategies must be implemented that will increase yields and shorten fermentation times. Probably the most likely method of accomplishing this will be to transfer the requisite plant genes those that code for the enzymes catalyzing the biosynthetic reactions required for the formation of the desired product - into a bacterial or fungal cell (21). This would be analagous to the method now employed for the commercial production of human insulin by bacteria. In terms of plant drugs, however, such developments lie in the future, not in the period covered by this review.

\section{Alkaloid Biosynthesis}

One of the research areas that has received much attention during the last 35 years is elucidation of the sites, pathways, and mechanisms of alkaloid biosynthesis in plant tissues and organs. Alkaloids probably were studied more comprehensively at an early date than other plant constituents for two reasons: 1. many have pronounced physiological activity and thus considerable drug potential, and 2 . because of their basicity, they are relatively easy to isolate.

Intense study in the 1950's and 1960's established the fundamental principles of biosynthesis and identified the main building blocks of the major alkaloids. As a result, investigators essentially confirmed the hypothesis advanced by Georg Trier in 1912 which stated that widespread plant constituents, especially amino acids, might be metabolized in a simple manner to heterocyclic alkaloids. They also verified many of the specific, theoretical pathways of alkaloid biosynthesis advanced by Robert Robinson in 1917 (22). Later investigation in the 1970's and even in this decade supplied additional mechanistic details and clarified the routes leading to certain complex alkaloids. The novel structure of colchicine provided a particulariy interesting biochemical challenge. Excellent books summarizing the known facts of alkaloid biosynthesis have appeared $(3,23)$.

What has emerged from all of this effort are some interesting basic principles. Alkaloid precursors are generally simple amino acids, such as, ornithine, lysine, phenylalanine, tyrosine, tryptophan, histidine, and anthranilic acid. These interact with simple acetate or terpenoid units and undergo aromatic hydroxylations and, occasionally, $O$ - and $N$-methylation with methionine to produce most alkaloids. The few remaining alkaloids are derived either from the purine nucleus or by the addition of ammonia or an alkylamine to a terpenoid-type nucleus.

One example of alkaloid biosynthesis which I find particularly interesting is hyoscyamine. As early as 1954, the role of ornithine as a precursor of the tropane moiety was clearly established. It was not until 1960 that phenylalanine was confirmed as giving rise to tropic acid. Details of the exact mechanism of this latter step, which involves an intramolecular shift of the carboxyl group, were still being worked out in the 1980's.

Perhaps the most intriguing example of biosynthetic complexity concerns the formation of the ergot alkaloids. By 1960 , it was eminently clear that both the clavine and lysergic acid types were formed by the condensation of tryptophan with an isoprene unit derived from mevalonic acid and a methyl group from methionine. But more than 25 years later, in spite of the tremendous efforts that have been made, many of the details are still unclear, and a unifying scheme for ergoline alkaloid biosynthesis is not yet possible.

\section{Psychotropic Drugs}

Albert Hofmann's discovery of the hallucinogenic effects of lysergic acid diethylamide (LSD) in 1943 stimulated a revival of scientific interest in plants and plant products with psychotropic or psychotomimetic properties. such interest was greatly enhanced by the publication, in 1957, of V. P. and R. G. Wasson's book Mushrooms, Russia and History. This work brought to bear on the field of hallucinogenic mushrooms findings from such diverse fields as folklore, religion, mycology, anthropology, linguistics, chemistry, pharmacology, and botanical exploration (24). It awakened an interest in the ethnopharmacology of psychotropic plants that was extremely intense for the next 10 years and which persisted, to a lesser extent, throughout the 1970's and 1980's.

In 1958, A. Hofmann and co-workers succeeded in isolating the active principles, psilocybin and psilocin, from a Mexican species of Psilocybe (25). The most poigant story in the modern scientific literature describes how he returned to Mexico and administered the potent hallucinogenic compound in the form of "pills" to the curandera Maria Sabina who had first revealed to non-natives the power of the "magic" mushrooms. She enthusiastically confirmed that the pill had the same power as the mushrooms and rejoiced that she could give her drug-induced consultations "even in the season when no mushrooms grow" (26).

Interest in hallucinogens was not restricted to mushrooms. Seeds of the ancient Aztec magicoreligious plant ololiuqui (Rivea corymbosa) were shown to contain ergine and other lysergic acid derivatives as their active principles (27). (Incidentally, the finding of such compounds in higher plants is not devoid of chemotaxonomic significance.) Then, in 1964, (-)$\Delta^{\prime} 3,4-$ trans-tetrahydrocannabinol, better known as $\Delta^{\prime}$-THC or 
just THC, was identified as the major active principle in marihuana or cannabis (Cannabis sativa) (28).

Other discoveries followed quickly. In 1964-1965, Japanese and Swiss groups headed, respectively, by Takemoto and Eugster, identified two isoxazole derivates, ibotenic acid and muscimol, as the hallucinogenic principles of the fly agaric ( $A$ manita muscaria) (29). Various tryptamines were subsequently confirmed as the active compounds in certain South American hallucinogenic snuffs.

Most of the developments up to 1967 were discussed at a conference, Ethnopharmacologic Search for Psychoactive Drugs, held in San Francisco that year and organized by Daniel $\mathbf{H}$. Efron of the National Institute for Mental Health. The published volume of proceedings of that conference has since become a classic in the field (30).

Studies after that date have been devoted mainly to cannabis - because of its widespread employment as a drug of abuse - and to ethnobotanic theories of the relationship of hallucinogenic plants and the mystical or religious experiences of human beings. R. G. Wasson has propounded several such theories including his belief that Amanita muscaria was the soma of the ancient Aryans and that water-soluble ergot alkaloids were responsible for the effects experienced by pilgrims during the course of the Grecian Eleusinian mystery rites (31).

Although much effort has been expended on psychotropic plants during the last 35 years and much of basic interest has been learned, the disappointing feature is the lack of development of any truly useful drug from all this research. Perhaps the closest approach is the use of THC to suppress nausea resulting from cancer chemotherapy, but even that application remains controversial. It was hoped that research on hallucinogens would provide a deeper insight into the cause and cure of certain types of mental illness. That favorable result has not yet been realized.

\section{Plant Chemotaxonomy}

The application of chemistry to plant systematics dates back more than 150 years, but much progess has been made in the field in the last 35 years. This has been due, in large measure, to improved procedures which facilitate the isolation and structure determination of chemical compounds from plant sources. Interest in the field has been based on the assumption that biochemical characters are more significant as systematic features than are morphological characters because the former are affected only in a quantitative way by modifiers whereas the latter may be qualitatively influenced.

Alston and Turner have described the period of biochemical systematics as beginning in the early 1950's (32). It has been characterized in its initial stages by the establishment of biochemical profiles for various plant taxa and the use of them for solving taxonomic problems. Certainly the greatest contribution since 1962 to the development of the science has been the projected 9 volumes ( 7 have appeared to date) of Chemotaxonomie der Pflanzen by R. Hegnauer (33). This work has proven extremely useful to those interested in the occurrence of certain constituents or types of constituents in various plant taxa.

In terms of helping establish the relationship of one plant to another, the full potential of chemical constituents has yet to be realized. The most utility is attainable in areas where other features are relatively few or difficult to determine, as is the case with many species of basidiomycetes (34). Then, too, it must be recognized that convergence and divergence occur with respect to molecular characteristics (chemical compounds) just as they do in the case of morphological features. The full potential of the chemotaxonomic method will not be achieved until we are able to catalog the exact sequence of nucleotides in the DNA molecules of the species being examined. Until then, the method with its dependence on the vagaries of secondary metabolite formation and degradation will continue to be an imperfect one.

\section{Antibiotics}

This has been a most disappointing field of research endeavor during the past 35 years. Not a single, clinically useful antibiotic has been identified in a higher plant in that period. Further, most of the commercially important products of microbial origin, including penicillin, erythromycin, tetracyclines, etc., were discovered prior to 1953. While the first cephalosporin antibiotic was isolated in 1955-1956 and two commercial cephalosporins appeared in 1964, the latter products and all subsequent ones are semisynthetic derivatives, not true natural products.

One significant breakthrough in the field did occur in 1976 with the isolation of clavulanic acid from Streptomyces clavuligerus (35). The compound was found to enhance the action of penicillins and cephalosporins by inactivating a wide variety of $\beta$-lactamases, particularly those responsible for transferred drug resistance to these antibiotics. It acts by blocking the active sites of such enzymes. Commerical products now available are combinations of antibiotics and clavulanic acid salts.

With regard to antibiotic research, Cordell (36) has posed a most interesting question. In view of the high cost of development and government approval, the limited use, and the consequent exorbitant cost to the consumer of new antibiotics, "... at what point does the development of more sophisticated antibiotics for more resistant infection stop . . ?" He suggests that it is time for drug companies to turn their research efforts to other, more productive fields.

\section{Some Significant Plant Drugs}

\section{Catharanthus roseus}

Beginning in the mid-1950's, two research groups, one Canadian, the other American, undertook independent phytochemical and pharmacological investigations of Catharanthus roseus based on the plant's folkloric reputation as an oral hypoglycemic agent. The observation that certain fractions produced peripheral granulocytopenia and bone marrow depression in rats led the Canadian investigators to isolate vinblastine (VLB) in 1958. After noting activity of an extract against P-1534 leukemia in mice, the American group isolated vincristine (VCR) in 1961. These two dimeric indole alkaloids have become the most important clinically useful anticancer agents from any plant source (6). This has occurred in spite of the fact that VLB and VCR are relatively minor alkaloids, occurring in admixture with some 90 others, to the extent of $1 \mathrm{~g}$ and $20 \mathrm{mg}$ per $1000 \mathrm{~kg}$ of plant material, respectively (23).

Perhaps even more significant than the actual discovery of these two important anticancer drugs was the impetus which the discovery gave to the search for other new antineoplastic agents. In the 1960's, the National Cancer Institute (Drug Research and Development Branch) of the United States initiated a program of screening plant species for animal antitumor activity. During 
the next 25 years, some 40,000 different plants were investigated, a program characterized as the most extensive pharmacological investigation of plants ever conducted $(9,37)$. Unfortunately, the program failed to identify a single agent of general use in the treatment of human cancer, probably due in large measure to the failure of chemists, biologists, and physicians to interact effectively in the effort.

Thus, some 30 years after their discovery, the alkaloids vinblastine and vincristine remain the only two commercially available anticancer drugs isolated from any higher plant. While this is disappointing, it must be remembered that the cost of the unsuccessful (thus far) NCI effort has certainly been no greater than the cost of many of the unsuccessful programs aimed at developing new synthetic drugs. It should also be noted that during this period several new, commercially available antibiotics with antineoplastic activity have been obtained from microorganisms. Detailed consideration of them is, however, beyond the scope of this presentation.

\section{Rauwolfia}

Of 8 new prescription drugs from natural sources introduced into medical practice in the United States during the period 1954 to 1973,2 were the catharanthus alkaloids just discussed, 5 of the remaining 6 were obtained from the root of Rauwolfia serpentina (37). As was the case with catharanthus, the importance of the discovery of this tranquilizer-antihypertensive natural drug extended far beyond itself (1). It served not only to stimulate developments in the fields of hypertension treatment, geriatrics, gynecology, and psychiatry but, most important for us, in medicinal plant research as well.

\section{Ergot}

Ergot has been mentioned repeatedly in this review, first in regard to its field cultivation, again in connection with studies of the biosynthesis of its alkaloids and, finally, in the section on psychotropic drugs. Further consideration must be given to a finding of immense importance with respect to the present-day commercial production of its alkaloids. Although parasitic field cultivation may still be carried out in some parts of the world, the 1960 finding of Arcamone et al. (38) that Claviceps paspali produced lysergic acid derivatives in submerged culture opened up a productive course of research that has led, at the present time, to the development of saprophytic commercial production techniques for both the water-soluble and the peptide ergot alkaloids. This has been one of the landmark achievements of the past 35 years.

\section{Milk Thistle}

Isolation of silymarin (silybin) from the fruit of the milk thistle (Silybum marianum) by Wagner et al. in 1968 (39) and subsequent investigations of the physiological activity of this new flavonolignan raised hopes that a useful therapeutic agent for the treatment of liver dysfunction had been discovered. Indeed, that hope has been partially realized.

Animal studies suggest its value in poisoning by amanita toxins, and investigations in human patients have yielded some success in other hepatic disorders, such as hepatitis and cirrhosis. A number of commercial products are available in Europe. However, as noted in Martindale, the clinical evidence of its efficacy is sparse, and some studies cast doubt on its hepatoprotective role in human beings (40). For this reason, the drug is still not marketed in the United States.

\section{Chamomiles}

Chamomiles are perhaps best characterized as enigmatic drugs. Scarcely recognized as medicinals in the United States, both German and Roman chamomiles have been the subject of continuous study in Europe during the past 35 years. Both are used there as ingredients in medicinal teas as well as in a large number of pharmaceutical products. Investigations range from chemical studies of chamomile volatile oil and its constituents to evaluation of the anti-inflammatory and antispasmodic action of the plants. Some idea of the concentrated effort devoted to the chamomiles may be gained from the comprehensive review of the subject by Mann and Staba which lists 207 references to studies conducted between 1953 and 1986 (41).

\section{Herbal Remedies}

In concluding this section on significant or potentially significant plant drugs, it seems appropriate to consider two of the very large number of herbal remedies that are enjoying great popularity at the moment due to the resurgence of interest in all things "natural" and "organic". Specifically these are garlic and ginseng $(42,43)$. The two are alike in many ways. Both have been the subject of considerable research in the past 35 years, and significant discoveries have been made regarding the chemical nature of their constituents. What remains to be done with both, and indeed with a very large number of other herbal products $(44,45)$ is to carry out appropriate clinical trials using welldesigned modern protocols, that is, double-blind, crossover studies, to determine the exact qualitative and quantitative nature of their physiological effects in human beings. Until that is done, we really can make no positive statements about the therapeutic utility of either product.

\section{Summary and Conclusions}

As Farnsworth has pointed out, about $25 \%$ of the prescription drugs used in industrialized nations contain ingredients extracted from higher plants, a situation that has not changed appreciably in the last 25 years (46). However, in view of the immense amount of work devoted to plant drugs during that period, it should be of concern to every scientist interested in them that the percentage has not increased. Indeed, since the founding of this Society in 1953, the only really new, commercially available drugs from higher plants, which have had their therapeutic efficacy and utility proven beyond doubt, have been the catharanthus alkaloids.

Looking backward with the clear vision provided by our modern vantage point, we realize that our efforts at drug discovery could have been much more efficient. It is a real pity that the hundreds of thousands of extracts, fractions, and purified constituents derived from plants examined in the American $\mathrm{Na}$ tional Cancer Institute screening program could not have undergone broader physiological testing. The same is true for all of the fermentation broths from microorganisms examined by drug companies in their antibiotic screening programs. If materials from both these sources had been subjected to evaluation by the Hippocratic screen or even by a method as simple as the brine shrimp assay, I dare say our materia medica would be much richer for it.

Although our search to date has yielded only modest success, we should not forget that we have discovered much better ways of looking for new plant drugs. We have certainly learned much 
about the basics of plant metabolism, plant analysis, and even plant production. Our methods of research have never been better, and there are still scores of thousands of readily available species awaiting investigation or reinvestigation.

My personal belief is that the most productive period of medicinal plant research lies ahead of us. Remember, it took only one satellite orbiting the earth to provide a stimulus of mammoth proportions to the development of space travel. Somewhere, perhaps under our very noses, lies that one plant, the constituents of which will certainly cure cancer, AIDS, or even protect against the afflictions of old age. The significant research results of the last 35 years have developed the means by which it can be found. I wish you much success and just a little bit of good luck in your endeavors to find it. The end result will make it all worthwhile.

\section{References}

(1) Woodson, Jr., R. E., Youngken, H. W., Schlittler, E., Schneider, J. A. (1957) Rauwolfia: Botany, Pharmacognosy, Chemistry \& Pharmacology, 149 pp., Little, Brown and Company, Boston.

(2) Heftmann, E., Ed. (1975) Chromatography: A Laboratory Handbook of Chromatographic and Electrophoretic Methods, pp. 113, Van Nostrand Reinhold Company, New York.

(3) Mothes, K., Schütte, H. R., Luckner, M. (1985) Biochemistry of Alkaloids, 406 pp., VCH Publishers, Deerfield Beach, Florida.

(4) Tyler, V. E., Brady, L. R., Robbers, J. E. (1981) Pharmacognosy, 8 th edn., 520 pp., Lea \& Febiger, Philadelphia.

(5) Djerassi, C. (1979) The Politics of Contraception, 274 pp., W. W. Norton \& Company, New York.

(6) Taylor, W. I., Farnsworth, N. R., eds. (1975) The Catharanthus Alkaloids, 323 pp., Marcel Dekker, Inc., New York.

(7) Stahl, E. (1956) Pharmazie 11, 633-637.

(8) Gouw, T. H., Jentoft, R. E. (1972) in: Guide to Modern Methods of Instrumental Analysis (Gouw, T. H., ed.), pp. 43-81, John Wiley \& Sons, Inc., New York.

(9) Tyler, V. E. (1986) Econ. Bot. 40, 279-288.

(10) Malone, M. H. (1977) in: New Natural Products and Plant Drugs with Pharmacological, Biological or Therapeutic Activity (Wagner, H., Wolff, P., eds.), pp. 23-53, Springer-Verlag, Berlin.

(11) Schieder, O. (1984) in: Biogene Arzneistoffe (Czygan, F.-C., ed.) pp. 177-200, Friedr. Vieweg \& Sohn, Braunschweig.

(12) Heeger, E. F. (1956) Handbuch des Arznei- und Gewürzpflanzenbaues, 776 pp., Deutscher Bauernverlag, Berlin.

(13) Tyler, V. E. (1962) J. Pharmacy 3, 94-104.

(14) Sastry, K. S. M., Atal, C. K., Kapur, B. M. (1985) Ergot Production in India, 143 pp., Regional Research Laboratory, JammuTawi.

(15) Fairbairn, J. W. (1976) Planta Med. 29, 26-31.

(16) Neubauer, D., Mothes, K. (1963) Planta Med. 11, 387-391.

(17) Holden, C. (1975) Science 190, 1274.

(18) Ebert, K. (1982) Arznei- und Gewürzpflanzen, 221 pp., Wissenschaftliche Verlagsgesellschaft $\mathrm{mbH}$, Stuttgart.

(19) West, F. R., Mika, E. S. (1957) Bot. Gaz. (Chicago) 119, 50-54.

(20) Nickell, L. G. (1980) in: Plant Tissue Culture as a Source of Biochemicals (Staba, E. J., ed.), pp. 235-269, CRC Press, Inc., Boca Raton.

(21) Heinstein, P. (1985) J. Nat. Prod. 48, 1-9.

(22) Mothes, K. (1959) in: Utilization of Nitrogen and its Compounds by Plants (Porter, H. K., ed.), pp. 258-282, Academic Press, Inc., New York.

(23) Cordell, G. A. (1981) Introduction to Alkaloids: A Biogenetic Approach, 1055 pp., John Wiley \& Sons, New York.

(24) Wasson, V. P., Wasson, R. G. (1957) Mushrooms, Russia and History, 2 Vols., 433 pp., Pantheon Books, New York.

(25) Hofmann, A., Heim, R., Brack, A., Kobel, H. (1958) Experientia $14,107$.
(26) Hofmann, A. (1980) LSD: My Problem Child, pp. 139-144, McGraw-Hill Book Company, New York.

(27) Schultes, R. E., Hofmann, A. (1973) The Botany and Chemistry of Hallucinogens, 267 pp., Charles C Thomas, Springfield, IIlinois.

(28) Mechoulam, R. (1973) in: Marijuana (Mechoulam, R., ed.), pp. 1-99, Academic Press, Inc., New York.

(29) Tyler, V. E., Jr. (1966) Lloydia 29, 275-292.

(30) Efron, D. H., ed. (1967) Ethnopharmacologic Search for Psychoactive Drugs, Public Health Service Publication No. 1645, 468 pp., U. S. Government Printing Office, Washington, D. C.

(31) Wasson, R. G., Hofmann, A., Ruck, C. A. P. (1978) The Road to Eleusis, $126 \mathrm{pp}$., Harcourt Brace Jovanovich, Inc., New York.

(32) Alston, R. E., Turner, B. L. (1963) Biochemical Systematics, p. 39, Prentice-Hall, Inc., Englewood Cliffs, New Jersey.

(33) Hegnauer, R. (1962-86) Chemotaxonomie der Pflanzen, Vols. 17, Birkhäuser Verlag, Basel.

(34) Tyler, V.E., Jr. (1971) in: Evolution in the Higher Basidiomycetes (Petersen, R. H., ed.), pp. 29-62, The University of Tennessee Press, Knoxville.

(35) Cherry, P. C., Newall, C. E. (1982) in: Chemistry and Biology of B-Lactam Antibiotics, Vol. 2, Nontraditional $\beta$-Lactam Antibiotics (Morin, R. B., Gorman, M., eds.), pp. 361-402, Academic Press, Inc. New York.

(36) Cordell, G. A. (1987) Am. Drug. 195(3), 96-98.

(37) Farnsworth, N. R., Bingel, A. S. (1977) in: New Natural Products and Plant Drugs with Pharmacological, Biological or Therapeutic Activity (Wagner, H., Wolff, P., eds.), pp. 1-22, Springer-Verlag, Berlin.

(38) Arcamone, F, , Bonino, C., Chain, E. B., Ferretti, A., Penella, P., Tonolo, A., Vero, L. (1960) Nature 187, 238-239.

(39) Wagner, H. (1981) in: Natural Products as Medicinal Agents (Beal, J. L., Reinhard, E., eds.), pp. 217-242, Hippokrates Verlag, Stuttgart.

(40) Reynolds, J. E. F., ed. (1982) Martindale: The Extra Pharmacopoeia, 28th edn., p. 1753, The Pharmaceutical Press, London.

(41) Mann, C., Staba, E. J. (1986) in: Herbs, Spices, and Medicinal Plants: Recent Advances in Botany, Horticulture, and Pharmacology, Vol. 1, (Craker, L. E., Simon, J. E., eds.), pp. 235280, Oryx Press, Phoenix, Arizona.

(42) Becker, H. (1985) Dtsch. Apoth. Ztg. 125, 1677-1680.

(43) Sonnenborn, U. (1987) Dtsch. Apoth. Ztg. 127, 433-441.

(44) Tyler, V. E. (1985) in: Examining Holistic Medicine (Stalker, D., Glymour, C., eds.), pp. 323-339, Prometheus Books, Buffalo, New York.

(45) Tyler, V. E. (1986) Pharm. Int. 7, 203-207.

(46) Farnsworth, N. R. (1984) in: Natural Products and Drug Development (Krogsgaard-Larsen, P., Christensen, S. G., Kofod, H., eds.), pp. 17-30, Munksgaard, Copenhagen. 